\title{
O USO DE UM JOGO DE BATALHA NAVAL COMO FERRAMENTA DIDÁTICA NO ENSINO DE MATEMÁTICA NA EDUCAÇÃO BÁSICA
}

\author{
THE USE OF A NAVAL BATTLE GAME AS A TEACHING TOOL IN \\ MATHEMATICS EDUCATION IN BASIC EDUCATION
}

\author{
João Pedro Mardegan Ribeiro ${ }^{1}$ \\ Universidade de São Paulo - USP
}

\begin{abstract}
Resumo
Por consequência de estudos que começaram com maior ênfase nos anos setenta, como nos trabalhos de David Ausubel, Paulo Freire e Howard Gardner, sabe-se que os alunos apresentam perfis subjetivos de aprendizagem, assim, de certo, a velocidade e a forma de apropriação do conhecimento varia conforme o sujeito objeto dos paradigmas ensino e aprendizado. De maneira geral, sendo o professor o responsável por transformar um conjunto de matérias em conteúdo de ensino, deve ele criar seu plano de aula de forma que a maioria dos alunos participem da interação com o conteúdo. Hoje, nota-se que a aula expositiva-dialogada está defasada, uma vez que os alunos não sentem atraídos em serem agentes passivos na relação de ensino e aprendizado, ou seja, não sentem atraídos em ficar em silêncio apenas ouvindo o professor. Atrelado ao pensamento de que o professor deve integrar outras metodologias em suas aulas para garantir que os alunos adquiram uma aprendizagem significativa, como também haja uma maior quantidade de alunos participando da interação com o conteúdo, este trabalho teve como finalidade analisar a influência de um jogo de batalha naval como ferramenta didática no ensino de matemática para com alunos do ensino fundamental, testando se este pode ser um possível apoiador das aulas expositivas para melhora nos índices de desempenho dos alunos. Esta pesquisa consistiu em uma análise de desempenho dos alunos apenas com a aula expositiva, como também após a aplicação do jogo. Com base nos resultados obtidos notou-se que houve melhora no desempenho dos alunos após esta abordagem metodológica, mostrando a grande eficiência da integração de jogos em aulas de matemática.
\end{abstract}

Palavras-chave: Recurso Didático; Jogo; Batalha naval; matemática

\begin{abstract}
As a result of studies that began with greater emphasis on the seventies, such as the works of David Ausubel, Paulo Freire and Howard Gardner, it is known that students have subjective learning profiles, thus, certainly, the speed and form of appropriation of knowledge varies according to the subject object of the teaching and learning paradigms. Generally speaking, with the teacher being responsible for transforming a set of subjects into teaching content, he or she should create his or her lesson plan so that most students participe in the interaction with the content. Today, it is noted that the lecture-dialogued class is outdated, since students are not attracted to be passive agents in the teaching-learning relationship, they are not attracted to be silent just listening to the teacher. Coupled with the thought that teachers should integrate other

\footnotetext{
1 joao.mardegan.ribeiro@usp.br
} 
methodologies into their classes to ensure that students acquire meaningful learning, as well as more students participating in the interaction with content, this paper animed to analyze the influence of a game of naval battle as a didactic tool in the teaching of mathematics to elementary students, testing if this can be a possible supporter of lectures to improve student performance rates. This research consisted of an analysis of student performance only with the lecture, as well as after the application of the game. Based on the results obtained it was noted that there was an imporvement in student performance after this methodological approach, showing the great efficiency of the integration of games in math classes.

Keywords: Didactic resource; game; naval battle; mathematics.

\section{Introdução}

Muito se tem discutido ao redor do mundo acerca do método tradicional de Ensino, denominado "aula expositiva-dialogada". Com base em estudos teóricos, notase que esta é pouco dialogada, uma vez que os alunos são tratados como agentes passivos no processo de Ensino, ou seja, apenas recebem o conhecimento em sua forma final. Referente ao ensino das ciências exatas, tais quais: física, química e matemática, o conteúdo propriamente dito dificulta o diálogo entre o professor e o aluno, o que acaba acontecendo é que os alunos criam aversões a estas matérias, fazendo com o aprendizado seja dificultado.

De maneira assertiva, quando o aluno é posto como agente passivo no processo de ensino e de aprendizagem, a dificuldade de acontecer uma aprendizagem significativa é grande, favorecendo o aprendizado mecânico. Sendo o aprendizado mecânico aquele em que ocorre quando o aluno aprende o novo conteúdo de forma arbitrária, ou seja, sem entender do que se trata, e para que serve, decora apenas um fim imediato, que é a realização de uma prova ou exame. Em matemática significa que o aluno decora como fazer certos cálculos para uma avaliação (necessidade de aprovação temporária), e depois de um certo tempo já não sabe mais como fazer.

O conteúdo de matemática é oriundo de uma ordem gradual, sendo este importante já que auxilia na compreensão de conhecimentos de outras áreas. Essa ordem gradual significa que o conhecimento matemático vai crescendo conforme o passar dos anos escolares, onde o conhecimento adquirido no ano anterior é necessário para o entendimento de um novo conceito.

Acontece que o método tradicional de ensino, onde o professor atua na sala de aula, expondo o conteúdo em sua forma final, abordando apenas fórmulas prontas e 
como usá-las está defasado, uma vez que os alunos não sentem atraídos em apenas ficar ouvindo o professor falar um monte de conteúdos que para eles não tem significado e contexto, ou seja, sem aplicabilidade, acarretando assim, em salas barulhentas (alunos não respeitam os professores e ficam conversando), ou em salas silenciosas, onde os alunos estão dormindo, ou prestando atenção, mas não entendendo nada.

Os professores em geral mostram a matemática como um corpo de conhecimentos acabado polido. Ao aluno não é dado em nenhum momento a oportunidade ou gerada a necessidade de criar nada, nem mesmo uma solução mais interessante. $\mathrm{O}$ aluno assim passa a acreditar que na aula de matemática o seu papel é passivo e desinteressante (D’AMBRÓSIO,1989 p.14-19).

Assim, devido a métodos ineficazes, a aprendizagem não acontece. De maneira geral, observa-se que expor o conteúdo na lousa e explica-lo é importante, porém este método não deve ser trabalhado isoladamente. Ao método tradicional deve ser integrado outras metodologias de ensino, uma vez que os alunos apresentam perfis subjetivos de aprendizagem, sendo assim, não aprendem com a mesma velocidade e tão pouco da mesma forma.

Há muitas metodologias que integradas a aula expositiva auxiliam no processo de ensino, sendo elas: o estudo de texto, a tempestade cerebral (brainstorming), estudo dirigido, utilização de meios informativos, as tecnologias da informação, dramatização ou cantoria, seminário, estudo de meio, estudo de caso, o método investigativo e os jogos. Todos estes citados possuem suas particularidades e distinções, todavia, se o professor conseguir correlacionar a exposição com um destes, a garantia de uma aprendizagem significativa aumenta ainda mais.

A aplicação de jogos em sala é uma metodologia inovadora que vem sendo estudada por muitos pesquisadores para testar a visibilidade desta. Alguns laboratórios de pesquisa em educação, programas de estágio supervisionado e alguns programas de iniciação à Docência como o PIBID - Programa Institucional de Bolsas de Iniciação à docência, os professores responsáveis solicitam a criação e aplicação de jogos em sala de aula.

O pensamento acerca dos jogos é que este possibilita que haja uma maior participação dos alunos na aula (há grande interação aluno-aluno e também alunoconteúdo). De fato, os alunos sentem a necessidade de participação (para que haja 
interação), assim eles precisam aprender os princípios e funcionamento do jogo para poder adentrar neste universo. Trabalhar com jogos é uma das formas de explorar a subjetividade do sujeito, já que os alunos não percebem que estão participando de uma aula onde ele é o agente ativo.

Piaget afirma que quando uma criança interage com o mundo à sua volta, ele atua (interna e externamente) e muda a realidade que vivencia. Para que isso ocorra, a criança deve ter um esquema de ação. É por meio do esquema de ação que a criança organiza e interpreta a ação, para que esta seja praticada. É uma estratégia de ação generalizável, de forma que a criança consiga se adaptar às mudanças ocorridas no seu meio (Fossile, 2010).

De maneira geral, os jogos são classificados como um esquema de ação, uma vez que potencializa as condições de aprendizado de conteúdo e estimula o pensamento/raciocínio lógico. Não há como participar do jogo sem saber suas regras e métodos, assim como, não há como jogar sem traçar estratégias e lógicas bem fundamentadas, afinal, quem joga não quer perder.

Tendo em vista dos aspectos ditos anteriormente, o objetivo pontual deste trabalho foi analisar se a aplicação de jogos em aulas de matemática poderia contribuir para que o índice de desempenho dos alunos melhorasse, e se esta ferramenta didática teria potencial integrador para com a aula expositiva.

\section{Fundamentação teórica}

Muitos professores hoje estão relatando acerca das dificuldades encontradas nas atividades de ensino-aprendizado de matemática na educação básica, assim estão procurando metodologias auxiliares a aula expositiva para suprir essa dificuldade.

Assim os jogos são meios utilizados para suprir essa dificuldade uma vez que estimula o raciocínio lógico frente a interpretações de situações problema. Para Alves (2001), atividades de ensino por meio de jogos estimulam significativamente as relações cognitivas, afetivas sociais, e proporcionam aos alunos habilidades e atitudes críticas. De fato, a sociedade atual exige cidadãos cada vez mais informados e que realizam atividades com mais agilidade e rapidez. Todavia, os jovens hoje são muito imediatistas, isso significa que eles não querem pensar e raciocinar acerca das coisas e sim querem tudo pronto e acabado. Mas, de fato a concorrência está cada vez mais crescendo, sendo 
assim, o melhor é aquele bem preparado. Para Dante (1999, p.11-12) é preciso desenvolver nos alunos habilidades de estímulos ao raciocínio lógico, tal como fazer o uso inteligente e eficaz dos recursos disponíveis, para que ele possa propor boas soluções frente a questões que surgem no dia-a-dia, na escola ou fora dela.

Os jogos são maneiras subjetivas de ensino, uma vez que os alunos não percebem que estão participando de uma atividade de aprendizado, e estes vêm para auxiliar na apropriação do conhecimento para com os alunos, mostrando significados entre o aprender e o brincar, fazendo uma ponte entre a compreensão do significado e a relação com objetos e acontecimentos da lógica-matemática. Para Grando (2001), o jogo requer uma participação ativa do aluno na construção do seu próprio conhecimento, como também favorece o desenvolvimento da criatividade, de senso crítico e a socialização.

Os alunos têm dificuldade em aprender a matemática e os jogos nesta disciplina servem no processo educativo para o desenvolvimento do raciocínio lógico. Com os mesmos tem a possibilidades de enxergarem outros conteúdos e desenvolvem outras habilidades, uma visão de novos conhecimentos (PIRES, 2009)

De certo, usar jogos como estratégias no ensino de matemática é uma maneira de fazer com que os jovens e adolescentes aprendam de uma maneira diferenciada o conteúdo, e de fato, desperta o interesse do aluno. Como a matemática é muitas vezes enquadrada como a vilã das disciplinas na educação básica, os professores cada vez mais tem buscado formas de minimizar esta visão adotando metodologias diferenciadas.

Quantas vezes não ouvimos que as matérias mais impopulares entre nossos alunos são Matemática e Língua! É assim por nossa culpa, porque não sabemos ensinar-lhes bem, de forma clara e atraente, com problemas curiosos e até divertidos, com atividades que ajudam a desenvolver a lógica e o sentido comum. Quantos bons professores despertam em seus alunos uma vocação profissional apenas com seu exemplo docente, porque nos fazem vibrar com suas explicações, com as atividades que são realizadas. (BATLLORI, 2006, p. 17)

Todos estão diretamente envolvidos com a matemática, seja direta ou indiretamente. Logo, é incontestável sua importância, uma vez que ela norteia toda a linguagem das relações humanas. O princípio da contagem está envolvido do momento do acordar até o momento de ir dormir, logo, ela é uma língua universal. 
A inserção dos jogos no contexto escolar aparece como uma possibilidade altamente significativa no processo de ensino aprendizagem, por meio da qual, ao mesmo tempo em que se aplica a ideia de aprender brincando, gerando interesse e prazer. (RIBEIRO, 2009, p. 19)

Os jogos exercem uma importância muito profunda no contexto educativo, uma vez que auxilia os alunos na resolução de problemas, estimulando e promovendo a criatividade e a cooperação no aprendizado, uma vez que necessita de investigar situações para boas jogadas e assim também desenvolvendo o raciocínio lógico. Para Borin (1998) a introdução dos jogos em aulas de matemática possibilita a diminuição de bloqueios apresentados por muitos alunos que temem a matemática e sentem incapacidade de aprende-la. Assim, os jogos podem contribuir de maneira substancial no aprendizado de matemática, uma vez que atinge todos os alunos da sala, e não somente aqueles interessados nas aulas expositivas.

\section{Metodologia do trabalho}

Atrelado a visão de que os jogos podem contribuir de maneira substancial no processo de ensino-aprendizado de matemática visando uma aprendizagem significativa, o objetivo deste trabalho foi analisar se haveria melhora no desempenho dos alunos do ensino fundamental quando deparados a esta nova metodologia.

Este trabalho foi realizado em uma escola pública estadual localizada no município de São Carlos - SP, em parceira com o professor responsável pela turma do sétimo ano (ensino fundamental), e o conteúdo abordado para fazer a análise de desempenho foram os conceitos ditos como "3Ms da matemática", sendo estes: Moda, Mediana, Média (Aritmética e Ponderada). Assim, para a realização deste trabalho dividimos as atividades em três grandes etapas, sendo elas:

\section{ETAPA 1: Aula tradicional}

Durante quatro aulas desenvolvemos com os alunos por meio da metodologia tradicional de ensino, o conteúdo referente aos três Ms. Em cada aula um dos tópicos foi abordado, sendo: aula 1 - Moda, aula 2 - Média Aritmética, aula 3 - Média Ponderada, aula 4 - Mediana. Durante os trinta minutos iniciais da aula era explicado o conceito 
referente a cada um destes tópicos, e assim, partíamos para a resolução de exercícios simples, todos com aplicação direta dos conceitos e fórmulas. Indagávamos os alunos frente as questões para que estes participassem dos momentos de exposição. Nos vinte minutos finais de cada aula, os alunos realizavam uma pequena avaliação individual sobre a aula dada, a fim de verificar se estes conseguiram entender os conceitos e resoluções.

ETAPA 2: Jogo de batalha Naval dos 3Ms

Nesta etapa a sala foi dividida em seis grupos com seis alunos em cada um, e cada grupo era representado por um barquinho no jogo. Cada grupo recebeu questões de $\mathrm{A}$ à $\mathrm{R}$ (como coordenadas) e cada uma destas questões continha uma pergunta sobre média (aritmética ou ponderada), uma sobre mediana e uma sobre moda. Os jogadores só poderiam andar no tabuleiro, tal como atacar outro barquinho se acertassem todas as três questões.

As instruções eram as seguintes: o valor da moda era a coordenada para andar na horizontal, o valor da mediana era a coordenada para andar na linha vertical e o valor da média seria o ponto em vidas que seria retirado dos grupos em que eles atacassem.

Cada grupo começou o jogo com trinta pontos de vida, e assim, ganharia o grupo que conseguisse permanecer com mais vidas até o final deste. A duração do jogo foi de setenta minutos (uma aula e meia).

A ordem de realização das jogadas era do grupo 1 ao grupo 6 . O professor passava na bancada do grupo 1 e conferia se os três itens estavam corretos, se sim, eles poderiam fazer a jogada, caso estivesse errado, perderia a jogada e passaria para o próximo grupo, e assim, por conseguinte.

ETAPA 3: Provinha individual

Após a realização do jogo os alunos realizaram uma avaliação individual com questões semelhantes a realizada ao final de cada parte da etapa 1. Esta consistia de quatro questões, sendo uma de cada tópico abordado: uma de média aritmética, uma de média ponderada, uma de moda e uma de mediana. Esta atividade foi realizada nos vinte minutos finais da aula. 
João Pedro Mardegan Ribeiro

O uso de um jogo de batalha naval como ferramenta didática no ensino de matemática na educação básica

Tabela 1: Esquema do campo de batalha

\begin{tabular}{|l|l|l|l|l|l|l|l|l|l|l|l|l|l|l|l|l|l|l|l|l|}
\hline & 01 & 02 & 03 & 04 & 05 & 06 & 07 & 08 & 09 & 10 & 11 & 12 & 13 & 14 & 15 & 16 & 17 & 18 & 19 & 20 \\
\hline 01 & G6 & & & & & & & & & & & & & & & & & & & \\
\hline 02 & & & & & & & & & & & & & & & & & & & & \\
\hline 03 & & & & & & & & & & & & & & & & & & & & \\
\hline 04 & & & & & & & & & & & & & & & & & & & & \\
\hline 05 & & & & & & & & & & & & & & & & & & & & \\
\hline 06 & & & & & & & & & & & & & & & & & & & & \\
\hline 07 & & & & & G1 & & & & & & & & G3 & & & & & & & \\
\hline 08 & & & & & & & & & & & & & & & & & & & & \\
\hline 09 & & & & & & & & & & & & & & & & & & & & \\
\hline 10 & & & & & & & & G2 & & & & & & & & & & & & \\
\hline 11 & & & & & & & & & & & & & & & & & & & & \\
\hline 12 & & & & & & & & & & & & & & & & & & & & \\
\hline 13 & & & & & & & & & & & & & & & & & & & & \\
\hline 14 & & & & & & & & & & & & & & & & & & & & \\
\hline 15 & & & & & & & & & & & & & & & & & & & & \\
\hline 16 & & & & & & & & & & & & & & & & & & & & \\
\hline 17 & & & & & & & & & & & & & & & & & & & G4 & \\
\hline 18 & & & & & & & & & & & & & & & & & & & & \\
\hline 19 & & & & & G5 & & & & & & & & & & & & & & & \\
\hline 20 & & & & & & & & & & & & & & & & & & & & \\
\hline
\end{tabular}

Fonte: Elaborado pelo autor

\section{Análise e discussão dos dados}

$\mathrm{Na}$ primeira etapa que foi a realização das aulas expositivas, referente ao desempenho oral dos alunos, foi observado que eles participaram significativamente com o professor, uma vez que eles respondiam as perguntas e faziam interação com o conteúdo. Os alunos conseguiram obter um bom desempenho com as aulas tradicionais, e este resultado pode ser compreendido por esta sala ser muito participativa.

Tabela II - Desempenho dos alunos nas provinhas baseadas nas aulas expositivas

\begin{tabular}{|c|c|}
\hline CONTEÚDO & \% de acerto das questões \\
\hline Moda & $63,8 \%$ \\
\hline Média aritmética & $69,6 \%$ \\
\hline Média ponderada & $60,7 \%$ \\
\hline Mediana & $64,3 \%$ \\
\hline
\end{tabular}

Fonte: Dados coletados pelo autor 
Na segunda etapa que foi a aplicação do jogo de batalha naval, foi observado que os integrantes de cada grupo se auto ajudavam, uma vez que eles estavam empenhados na realização eficiente das jogadas. Observou-se também que muitos grupos distribuíram funções para cada membro a fim de acertar as questões o mais rápido possível para que assim pudessem atacar outros grupos. Foi observado também que os grupos não estavam apenas realizando a questão que gostariam de usar no momento, mas sim, estavam respondendo todas (de A à R) a fim de escolher a melhor alternativa para cada momento.

Dois grupos perderam todas as vidas e quatro chegaram ao final da aula com algumas vidas. O grupo campeão permaneceu com 17 vidas, e este era o grupo com os alunos com mais dificuldade em matemática (haviam apresentado menor quantidade de acertos nas questões dadas na etapa anterior).

$\mathrm{Na}$ terceira etapa que foi realizada após o jogo de batalha naval, foi medido o desempenho dos alunos de duas formas distintas, sendo elas: no gráfico I há o desempenho dos alunos antes e após a realização do jogo, para os alunos que realizaram todas as atividades (as quatro provinhas, uma de cada tópico, e também a atividade avaliativa ao final do jogo de batalha naval), e no gráfico II, há uma análise do desempenho de todos os alunos que realizaram as provinhas, independente se faltou em algum dos dias, ou não.

Gráfico I - Porcentagem de acerto antes e após o jogo - somente de quem realizou as cinco provinhas

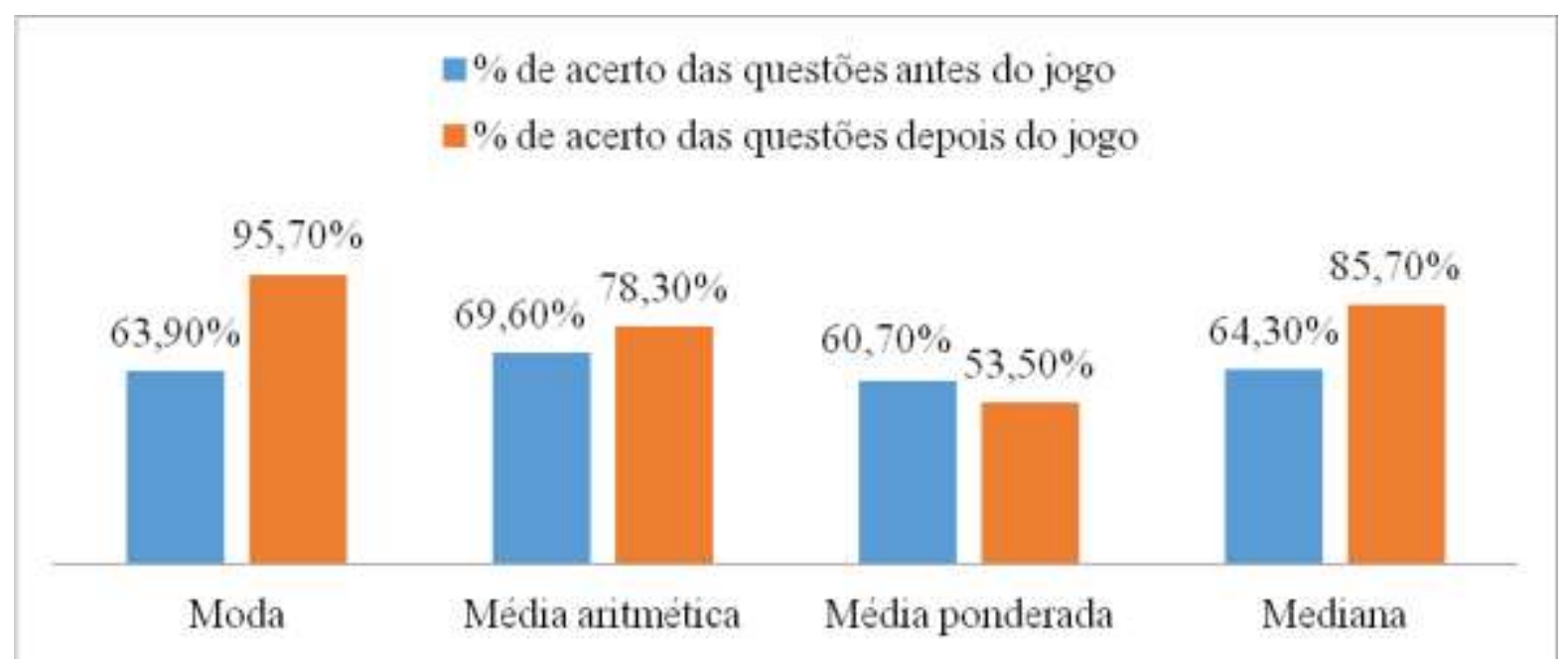

Fonte: Dados coletados pelo autor 
Com base no gráfico I, é notório o crescimento substancial no aumento de acertos em questões baseadas em Moda, e também em Mediana. No que se refere as médias, na média aritmética houve um pequeno aumento na quantidade de acertos, não muito expressivo, mas muito importante. Já em média ponderada, houve uma pequena queda de desempenho e isso se deu ao fato de que os alunos confundiram média ponderada com a aritmética.

Gráfico II - Porcentagem de acerto antes e após o jogo - Todos os alunos que realizaram as provinhas

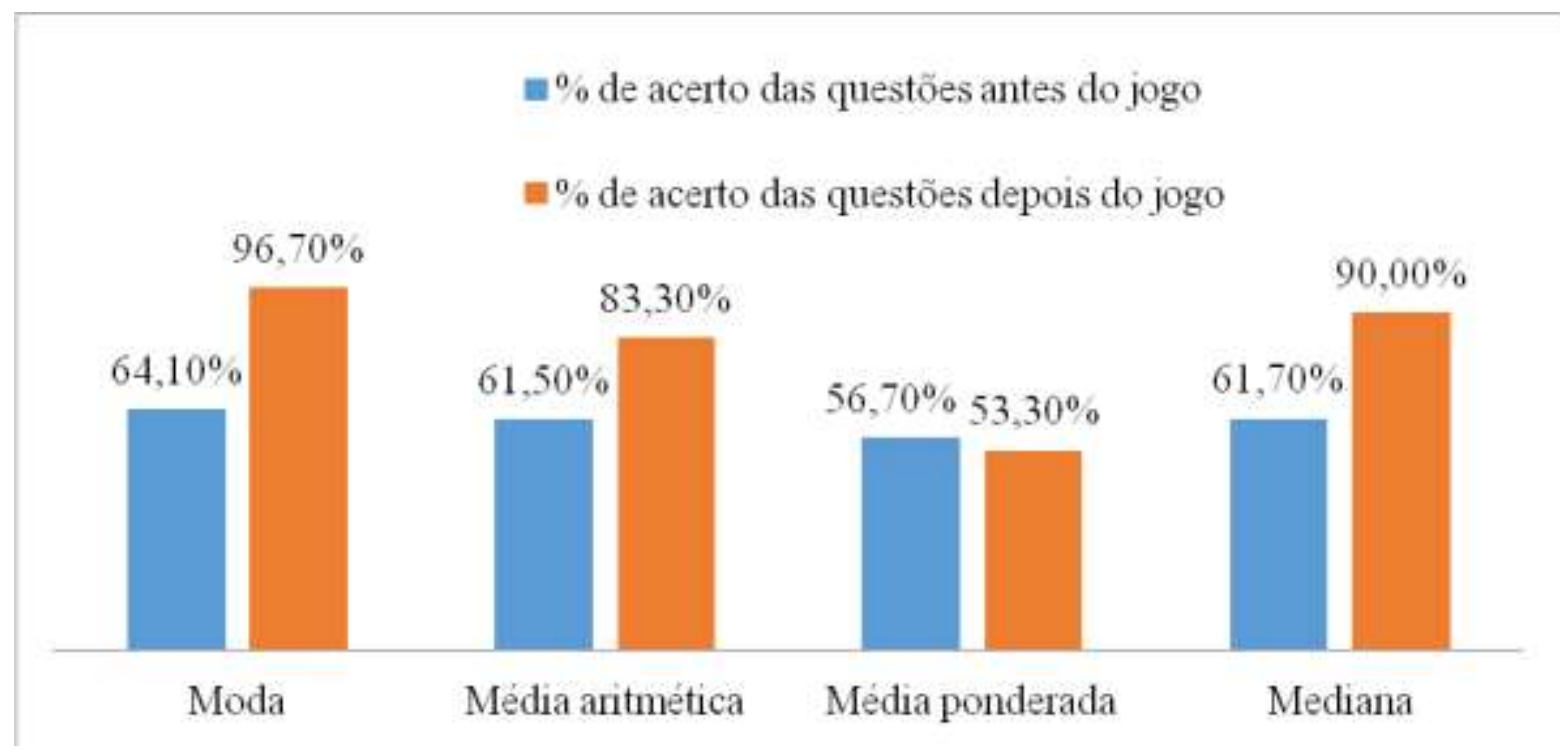

Fonte: Dados coletados pelo autor

De modo geral, analisando os dados obtidos e expostos nas tabelas e gráficos, percebemos que em três dos tópicos, sendo eles: Moda, Média Aritmética e Mediana, o desempenho dos alunos após o jogo aumentou consideravelmente. Somente o desempenho em média ponderada houve uma leve queda no desempenho, e assim, foi notado que uma grande parte dos alunos confundiu média ponderada com média aritmética, por isso houve índices não favoráveis referente ao desempenho neste tópico.

Tabela III: Índices de melhora de desempenho

\begin{tabular}{|c|c|}
\hline Conteúdo & $\begin{array}{c}\text { Índice de melhora dos alunos que realizaram } \\
\text { todas as atividades }\end{array}$ \\
\hline Moda & $50,0 \%$ \\
\hline Média Aritmética & $12,5 \%$ \\
\hline
\end{tabular}




\begin{tabular}{|c|c|}
\hline Média Ponderada & $-11,8 \%$ \\
\hline Mediana & $33,3 \%$ \\
\hline
\end{tabular}

Fonte: Elaborado pelo autor

Na tabela IV observa-se que houve uma melhora muito representativa nos índices de desempenho em moda e em mediana. $\mathrm{O}$ desempenho em média aritmética houve melhora mas não expressivo, e em média ponderada, houve um índice de queda, não substancial, todavia demonstra que os alunos confundiram os aspectos da média aritmética com os da ponderada.

De certo, a porcentagem de acertos somente com a aula expositiva foi boa, assim, os índices de melhora não atingiram valores superiores a 50\%. Referente a moda, os alunos após a realização do jogo atingiram um desempenho de 95,7\% de acerto, ou seja, quase todos os alunos acertaram estas questões. Em mediana também houve quase que totalidade na quantidade de acertos, atingindo 85,7\% de acerto. Esses dados são referentes aos alunos que realizaram ambas as cinco provinhas.

Média aritmética e média ponderada envolvem mais cálculos específicos do que propriamente a moda e a mediana que envolve mais análises de dados, isso se explica os índices de acerto superior em moda e mediana em comparação à média.

\section{Considerações finais}

De maneira geral, há quem credite o fracasso escolar (baixo desempenho dos alunos), em apenas a falta de disposição dos alunos em quererem aprender, todavia, esquecemos que é o professor o responsável qualificado por criar momentos de potencial, tal como de possibilitar que os alunos participem da interação com o conteúdo na construção do conhecimento. O professor também é o responsável por criar uma ponte significativa entre o conteúdo de ensino para com a realidade do aluno e o porquê de aprender tais fenômenos. Uma vez que o professor durante as aulas apenas faz uma abordagem tradicional, com uma aula expositiva-dialogada, está favorecendo uma aprendizagem mecânica, onde o aluno não terá interesse pelo conteúdo, podendo o aprender, todavia, como o conteúdo não terá onde se ancorar na cabeça dos alunos, ele será esquecido. 
Quando o homem compreende a sua realidade, pode levantar hipóteses sobre o desafio dessa realidade, e procurar soluções. Assim pode transformá-la e com seu trabalho pode criar um mudo próprio: seu eu e suas circunstâncias. [...]. A educação não é um processo de adaptação do indivíduo à sociedade. O homem deve transformar a realidade para ser mais (Freire, 1979, p. 30-31).

Nota-se que houve grande melhora no desempenho dos alunos após a abordagem do conteúdo com o jogo, e isto faz com que percebamos que novas metodologias didáticas podem ser inseridas em aulas de matemática para o aprimoramento do desempenho dos alunos. Jogos possibilitam que os alunos construam de forma indireta o conhecimento, ou seja, ele atua de forma indireta para a apropriação do conhecimento e saber nos alunos, garantindo melhora na aprendizagem.

De certo, pesquisas na área de Educação Matemática cada vez mais tem mostrado que os métodos expositivos não são os únicos meios de transmitir um conteúdo, assim faz-se necessário repensar e utilizar recursos diferenciados em sala de aula, buscando uma maior interação dos alunos. Muitos docentes já reconhecem que no ensino de matemática há uma carência lúdica que envolva os alunos em uma aprendizagem significativa.

De fato, os jogos devem ser vistos como um importante instrumento pedagógico que favorece a aprendizagem do aluno, e de maneira especial, os educandos percebem que é possível aprender matemática de uma forma divertida. Uma vez que nos momentos de jogos, os educandos não percebem que é um momento de aprendizagem, já que eles não correlacionam a atividade lúdica com a possibilidade de aprender matemática.

Em vista das atividades desenvolvidas, foi observado que o grupo com os alunos que apresentaram os índices mais baixos de desempenho após as aulas expositivas, obtiveram uma grande apropriação do conhecimento durante a atividade de batalha naval, o que levou este grupo a ganhar o jogo, e acertar quase que totalmente as questões após o mesmo.

Assim, nota-se que com a utilização de jogos, os alunos se esforçam para realizar as atividades e superar os obstáculos de aprendizado sem que percebam que estão realizando isto, assim, os obstáculos cognitivos e emocionais são superados, e os alunos sentem mais motivados e ficam mais ativos mentalmente. 
Sabemos que as experiências positivas nos dão segurança e estímulo para o desenvolvimento. O jogo nos propicia a experiência do êxito, pois é significativo, possibilitando a autodescoberta, a assimilação e a integração com o mundo por meio de relações e de vivências (KISHIMOTO, 1999, p.96)

Para Jose e Coelho (1997,p.15), quanto mais a criança espera de si mesma, e acha que os outros estão esperando dela, maiores serão seus motivos para atingir um objetivo. Em complemento a isso, Rossini (2005, p.75) diz que a emoção impulsiona a ação, fazendo com saiamos do estado de acomodação, superando nossos limites, assim, na medida em que somos e estamos motivados por sentimentos de entusiasmo e prazer no que estamos fazendo, estes sentimentos nos levam a conquistas.

Ou seja, de maneira geral, observou-se que os jogos integrados a aula expositiva-dialogada contribuíram de maneira significativa para a melhora no desempenho dos alunos. Uma vez que os alunos sentiram motivados e empenhados a jogar e participar da atividade, eles precisaram sanar as devidas dúvidas referentes aos conteúdos estudados para com os demais integrantes do grupo para que eles conseguissem desempenhar jogadas boas, corretas e eficientes.

Quando o aluno está individualmente realizando alguma atividade, e ele não conseguiu absorver o conteúdo com a aula expositiva, ele sente desmotivado a dar o melhor nesta atividade. No momento em que ele é posto em grupo com outros colegas, percebe a importância do conteúdo e percebe a importância da sua contribuição para auxiliar o grupo ele vai em busca do conhecimento.

Esta pesquisa mostrou qualitativamente e principalmente quantitativamente o quanto os jogos - atividades lúdicas, podem contribuir de maneira substancial no processo de ensino-aprendizado de matemática na educação básica, uma vez que seus índices foram expressivos e substanciais, demonstrando assim, que os jogos cada vez mais devem ser integrados ao plano de aula docente com a finalidade de a maior quantidade de alunos possível participe da apropriação do conhecimento.

\section{Referências}

ALVES, Álvaro Marcel Palomo. A Cultura Lúdica e sua constituição na cidade de Irati. Atos de pesquisa em educação - PPGE/ME FURB, Universidade Estadual do Centro Oeste (PR), v.5, n. 2, p. 167-188, maio/ago. 2010. 
ALVES, Eva Maria Siqueira. A ludicidade e o ensino da matemática: Uma prática possível. Campinas, SP: Papirus, 2001.

BARBOSA, P. M. R. O construtivismo e Jean Piaget. Educação Pública, publicado em 23 de Junho de 2015.

Disponível em: http://educacaopublica.cederj.edu.br/revista/artigos/o-construtivismo-ejean-piaget. Acesso em 25 de Fevereiro de 2018.

BATLLORI, Jorge. Jogos para treinar o cérebro: desenvolvimento de habilidades: cognitivas e sociais. Tradução de Fina Iñiguez. São Paulo: Madras, 2006.

BORIN, Júlian. Jogos e resolução de problemas: uma estratégia para as aulas de matemática. 6. ed. São Paulo: IME-USP, 1998.

D’AMBROSIO, B. S. "Como ensinar matemática hoje." Temas e debates 2.2 (1989): 15-19.

DANTE, Luiz Roberto. Didática da resolução de problemas de matemática. $1^{\mathrm{a}}$ à $5^{\mathrm{a}}$ séries-12º edição, editora Ática, 1999.

FOSSILE, Dieysa K. Construtivismo versus sócio-interacionismo: uma introdução às teorias cognitias. Revista Alpha, Patos de Minas, UNIPAM. 2010. Disponível em: http://alpha.unipam.edu.br/documents/18125/23730/construtivismo_versus_socio_intera cionsimo.pdf. Acesso em 18 de Janeiro de 2018.

GRANDO, Regina Célia. O jogo na educação: aspectos didático-metodológicos do jogo na educação matemática. Unicamp, 2001. Disponível em: http://www.damasciencias.com.br/institucional/O\%20Jogo\%20de\%20Damas\%20na\%2 0Educacao2.pdf. Acesso em 06/agosto/2019.

FREIRE, Paulo. Educação e Mudança. In: FREIRE, Paulo. Educação e Mudança. Rio de Janeiro: Paz e Terra, 1979. p. 30-31.

JOSÉ, E.; COELHO, M. Problemas de aprendizagem. São Paulo: Ática, 1997. Série Educação.

KISHIMOTO, Tizuko Morchida. (Org.). Jogo, brinquedo, brincadeira e a educação. 3. ed. São Paulo : Cortez,1999.

MARQUES, Marilaine de Castro Pereira; PERIN, Clailton Lira; SANTOS, Edinalva dos. CONTRIBUIÇÃO DOS JOGOS MATEMÁTICOS NA APRENDIZAGEM DOS ALUNOS DA $2^{\mathrm{a}}$ FASE DO $1^{\circ}$ CICLO DA ESCOLA ESTADUAL 19 DE MAIO DE ALTA FLORESTA-MT. Revista Eletrônica da Faculdade de Alta Floresta, Alta Floresta, v. 2, n. 1, p.0-21, 2013. Disponível em: <http://faflor.com.br/revistas/refaf/index.php/refaf/article/view/92/html>. Acesso em: 23 jul. 2017 
O uso de um jogo de batalha naval como ferramenta didática no ensino de matemática na educação básica

PIRES, Keila Almeida. O desenvolvimento do raciocínio lógico matemático por meio de jogos nas séries finais do ensino fundamental. Jussara-GO. 2009.

RIBEIRO, Flávia Dias. Jogos e Modelagem na Educação Matemática. 1. Ed. São Paulo: Saraiva, 2009. p.19

ROSSINI, M. Educar para ser escola. Petrópolis, RJ: Vozes, 2005. 